\title{
Dynamic surface water distributions influence wetland connectivity within a highly modified interior landscape
}

\author{
Blake A. Barbaree - Matthew E. Reiter • Catherine M. Hickey • \\ Nathan K. Elliott • Danica Schaffer-Smith • Mark D. Reynolds • \\ Gary W. Page
}

Received: 30 August 2017/ Accepted: 23 March 2018/Published online: 12 April 2018

(C) The Author(s) 2018

\begin{abstract}
Context Animal movements are inherently linked to landscape structure. Understanding this relationship for highly-mobile species requires documenting their responses to spatiotemporal variability of resources. To that end, characterizing movement behaviors and resource distributions using the principles of habitat connectivity facilitates coordinated landscape planning efforts within highly modified landscapes.

Objectives and methods We tracked locations and movements for 156 dunlin (Calidris alpina) and 109 long-billed dowitchers (Limnodromus scolopaceus) overwintering in two regions with distinct water distributions in California's Central Valley. We then compared residency rates, functional connectivity to
\end{abstract}

Electronic supplementary material The online version of this article (https://doi.org/10.1007/s10980-018-0638-8) contains supplementary material, which is available to authorized users.

B. A. Barbaree $(\varangle) \cdot$ M. E. Reiter .

C. M. Hickey · N. K. Elliott · G. W. Page

Point Blue Conservation Science, 3820 Cypress Drive

\#11, Petaluma, CA 94954, USA

e-mail: bbarbaree@pointblue.org

D. Schaffer-Smith

Nicholas School of the Environment, Duke University, Box 90328, Durham, NC 27705, USA

M. D. Reynolds

The Nature Conservancy, 201 Mission Street, 4th Floor, San Francisco, CA 94105, USA other regions, and associations between movement distances and average habitat availability and structural connectivity of habitat at multiple temporal and spatial scales.

Results A widespread yet highly variable regional water distribution was associated with lower residency rates and substantially higher functional connectivity to nearby regions when compared to a stable regional water distribution characterized by a large, contiguous wetland complex. Longer movements were associated with decreasing average availability and spatial aggregation of surface water. Movement models suggested shorebirds primarily responded to habitat availability at smaller scales $(<10 \mathrm{~km})$ and structural connectivity at larger scales $(\geq 10 \mathrm{~km})$.

Conclusions Differences in movement behaviors suggested that wintering shorebirds will avoid long distance movements and remain resident within a wetland region when possible. Conservation and management efforts should reliably flood individual wetlands and agricultural lands from November to April and prioritize locations that maximize structural wetland connectivity and limit spatiotemporal variability of surface water throughout the Central Valley.

Keywords Movement ecology · Landscape structure - Water distribution - Wetland connectivity · Landsat $\cdot$ Radio telemetry $\cdot$ Calidris alpina .

Limnodromus scolopaceus 


\section{Introduction}

The movement behaviors of migratory species are fundamentally linked to changes in resource abundance and distribution. This relationship is simplified during the "wintering" portion of their annual cycle because the physiological demands and spatiotemporal constraints of breeding or migrating are not present to influence movement decisions. Movements between habitat patches during the wintering period should only occur because of fluctuations in local resource availability or predation risk (Roshier et al. 2008). In landscapes that are highly modified by human activities, dynamic landscape structure, or the abundance and distribution of habitat resources, often results non-optimal movements between habitat patches that are induced by human activities (Fahrig 2007). Dynamic conservation and management efforts are essential in these landscapes (Knowlton and Graham 2010; Reynolds et al. 2017). Here, we investigate how movement behaviors are associated with spatiotemporal variability in landscape structure to inform strategic prioritization of conservation and management actions.

The relationship between landscape structure and movement behaviors can be characterized using the principles of habitat connectivity (Goodwin 2003). Within ecological landscapes there are two primary concepts of habitat connectivity: structural and functional. Structural connectivity can be measured as the spatial configuration of flooded habitats, whereas functional connectivity represents the degree to which movements among habitat patches occur given existing environmental conditions (Tischendorf and Fahrig 2000; Bélise 2005). Landscape conservation strategies require information on how functional connectivity is linked to structural connectivity because it can identify temporal and spatial habitat configurations that are potentially beneficial for certain species. This information is especially helpful when implementing coordinated conservation efforts for migratory shorebirds that rely on interior wetlands with highly managed and dynamically available freshwater resources (Haig et al. 1998; Taft and Haig 2006).

Data on habitat distributions for migratory shorebirds are temporally dynamic as well as sparse and coarse scale when considering that birds can move frequently and water distributions can fluctuate rapidly. Novel combinations of bird movement and habitat data are needed for inference on complex ecological tendencies when data are sparse and coarse scale (Neumann et al. 2015). Bird tracking technologies can provide broad scale movement data on small shorebirds currently, but a considerable investment into tracking efforts is required. Satellite imagery is more rapidly acquired and commonly used to delineate habitat availability for shorebirds over broad, static landscapes (e.g., Roshier et al. 2001; Toral et al. 2011), or landscapes averaged using data from consecutive years (e.g., Reiter et al. 2015; Schaffer-Smith et al. 2017). Combining temporally dynamic bird and habitat data will create a dataset that can inform conservation prioritization efforts when analyzed at multiple temporal and spatial scales (Wiens 1989; Albanese et al. 2012).

Prioritization of conservation investments within interior wetland landscapes requires assessing indicators of habitat to identify when and where limited funding resources should be focused. Seasonal residency and movement distances may be useful indicators of habitat quality for wintering shorebirds at broad scales because shorebirds usually avoid moving between wetland complexes unless the movement is advantageous to fitness or survival (Evans 1976; Kersten and Piersma 1987). Landscapes that facilitate mostly short, local movements by wintering shorebirds likely indicate high-quality habitat, which can lead to high survival rates (Drake et al. 2001), earlier arrival at breeding grounds, and attainment of better quality breeding sites (Alves et al. 2013). Habitat quality is also likely related to the spatial configuration of flooded habitats (structural connectivity) because it has been shown to influence movement decisions (Farmer and Parent 1997), habitat use, and local abundance of migratory shorebirds (Elphick 2008; Webb et al. 2010).

In this study, we documented the movements of both dunlin (Calidris alpina) and long-billed dowitchers (dowitchers; Limnodromus scolopaceus) overwintering in two regions with distinct and highly managed water distributions to better understand how wintering migratory shorebirds respond to changing landscape structure within the Central Valley, California, USA. Specifically, our objectives were to understand how shorebirds respond to spatiotemporal variation in the average amount and structural connectivity of surface water, and the degree of functional connectivity between two interior wetland regions. 
We predicted that functional connectivity between regions would increase from winter to spring as a result of decreasing seasonal residency rates (see Barbaree et al. 2015), and movement distances would increase in response to declining average habitat availability as well as decreasing structural connectivity of surface water. Results from this study provide a foundation for coordinated wetland and water management strategies that support both humans and migratory shorebirds in the Central Valley.

\section{Methods}

Study area

The low elevation $(<75 \mathrm{~m})$ Central Valley has a temperate climate and covers approximately $58,000 \mathrm{~km}^{2}$ within the interior of California, USA (Fig. 1). More than $90 \%$ of historic wetlands in the Central Valley have been modified or lost since the early part of the twentieth century (Frayer et al. 1989; Fleskes 2012), resulting in a reliance on waterbird habitats created by intentional flooding practices when sufficient freshwater is available. Since the mid-1990s when regulations were implemented to limit postharvest burning of agricultural lands, the post-harvest flooding of agricultural lands, primarily rice fields, from November to February has been shown to provide multiple benefits for landowners and waterbirds (Elphick and Oring 1998, 2003). Consequently, the removal of water from agricultural fields to prepare for planting results in declining surface water on the landscape from January to April with the average minimum extent occurring during early April (Schaffer-Smith et al. 2017). The availability of freshwater for flooding practices in the Central Valley is driven primarily by precipitation from November to April and run-off from the Sierra Nevada mountain range (Dettinger et al. 2011). Periods of drought occur frequently and our study coincided with a drought in northern California that progressed from a moderate drought during year one of the study (2012-2013) to an exceptional drought during year three (2014-2015; /www.droughtmonitor.unl.edu/; Griffin and Anchukaitis 2014).

We used three study regions defined by Central Valley Joint Venture (2006): (1) Sacramento Valley which was a mosaic of managed freshwater wetlands intermixed with seasonally flooded agricultural lands, (2) Yolo-Delta including Suisun Marsh which was largely managed freshwater and unmanaged intertidal wetlands, and (3) San Joaquin Basin including the Grasslands Ecological Area (GEA) and Mendota wetland complexes. Boundary modifications included truncating the northern boundary of the Sacramento Valley based on satellite imagery boundaries and extending the southern boundary of the San Joaquin Basin to include the Mendota Wildlife Area and adjacent wetlands. The total area of managed wetlands was similar between regions but their spatial configuration was not. There were approximately 29,884 ha of wetlands widely distributed in Sacramento Valley, 23,558 ha in Yolo-Delta (55\% of regional total in Suisun Marsh), and 27,185 ha in San Joaquin Basin (84\% in GEA; 9\% in Mendota). Agricultural lands with potential for post-harvest flooding included rice (219,082 ha; $94 \%$ of total in Sacramento Valley) and corn (105,613 ha; $87 \%$ in Yolo-Delta), in addition to other crops with irregular flooding practices (409,369 ha; $46 \%$ in San Joaquin Basin and 33\% in Yolo-Delta; Petrick et al. 2014; Dybala et al. 2017).

Shorebird capture and radio telemetry

We radio tagged a total of 96 dunlin and 67 dowitchers from November to January over three consecutive years in Sacramento Valley (2012-2015) and 60 dunlin and 42 dowitchers over two consecutive years in San Joaquin Basin (2012-2014); 1-1.5 g radio tags (Model NTQB-4-2; Lotek Wireless, Inc.) were attached to birds captured using mist nets, leg-noose mats, and air-powered net guns. In Sacramento Valley, we tagged 148 birds within six separate complexes of flooded rice fields and 15 birds in managed wetlands within Sacramento National Wildlife Refuge (NWR). In San Joaquin Basin, all captures occurred in managed wetlands within GEA, including Volta Wildlife Area, Los Banos Wildlife Area, Merced NWR, and two privately-owned wetland complexes.

To relocate radio-tagged birds, we conducted aerial surveys from a fixed-wing aircraft while flying primarily along established survey routes. We designed aerial survey routes to cover all flooded wetlands and agricultural lands in each region; we considered the probability of detection for a radiotagged bird located within the study area to be around 1.0 (see more details in Barbaree et al. 2016). We 
Fig. 1 Study area with regional boundaries and referenced locations in the Central Valley, California, USA

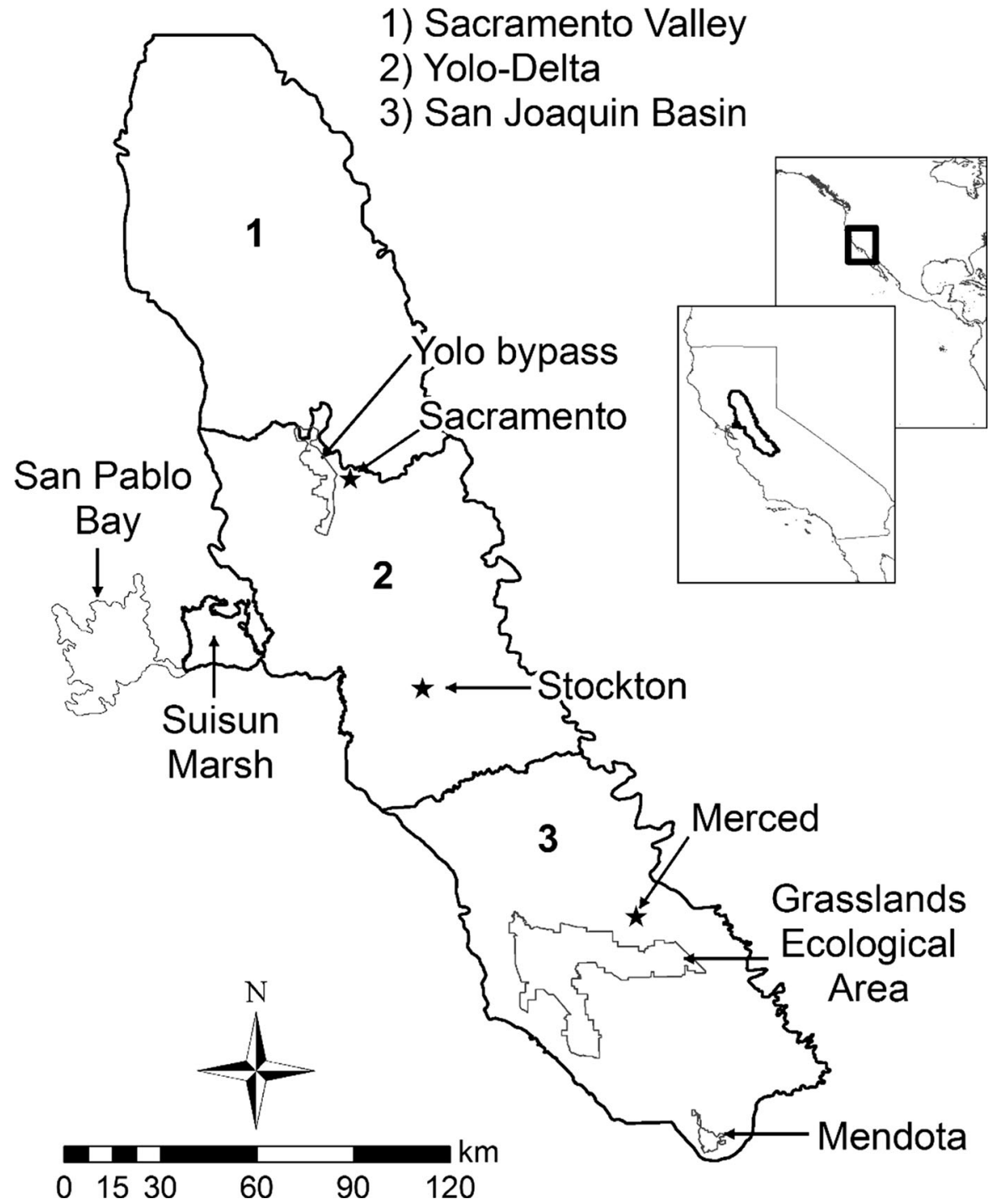

conducted a range test flight with radio tags placed in known locations on the ground to determine optimal transect width $(\sim 4.8 \mathrm{~km})$ and survey altitude $(700-1000 \mathrm{~m})$. We only surveyed when ground visibility was not reduced by fog or low clouds to ensure that all recently or temporarily flooded areas outside survey routes were surveyed.

We recorded an approximate location (latitude and longitude) for each radio-tagged bird detected during an aerial survey. If we detected a bird in an area with no water or the same location during two consecutive surveys, we visually determined if live shorebirds were present in the area while pinpointing the signal at low altitudes $(<300 \mathrm{~m})$; the mortality of three birds was later confirmed and data from those birds were not included in this study. To quantify a conservative estimate of the mean error associated with locations of radio-tagged birds, we conducted blind error tests simultaneously during two aerial surveys in January covering the Sacramento Valley. During error tests, radio tags were placed in locations unknown to the surveyor and within a flooded wetland or agricultural field. The mean Euclidean distance between the recorded and true location was $1007 \mathrm{~m}(95 \% \mathrm{CI}$ $661-1353 \mathrm{~m}$, median $=768 \mathrm{~m}, n=37)$. We later compared error rates to habitat data on the spatial aggregation of surface water and found that most bird 
locations were likely within the patch of habitat where the bird was actually located.

Aerial surveys occurred in Sacramento Valley $(n=27)$, Yolo-Delta $(n=25)$, and San Joaquin Basin $(n=23)$ every 16 days on average (ranging from 6 to 29 days) from late November to late April each year, which was consistent with similar studies (e.g., Taft et al. 2008). All three regions were surveyed equally during years one and two, but during year three, when we only tagged birds in Sacramento Valley, surveys of Yolo-Delta and San Joaquin Basin regions did not begin until late January when multiple radio-tagged birds were not located within the Sacramento Valley. In addition, to determine if birds from the Central Valley move into the adjacent San Francisco Bay region prior to migration, we conducted biweekly aerial surveys during March and April $2014(n=4)$ and $2015(n=4)$ that covered the coastline and wetlands associated with the northern portion of the San Francisco Bay estuary (San Pablo Bay and its tributaries).

\section{Water and habitat data}

We used satellite imagery to create maps that quantified the monthly average distribution of surface water from November to April (water availability index) within wetland and agricultural habitats potentially used by shorebirds (habitat type). Each cell of our gridded monthly maps was assigned a water availability index and a habitat type. Water availability indices were used to calculate three metrics that depicted month-to-month variability in the presence of surface water and structural connectivity of reliable surface water.

\section{Water availability indices}

We created monthly habitat maps depicting average water availability at $30 \times 30 \mathrm{~m}$ resolution. We used Landsat satellite images with $<50 \%$ cloud cover from November to April that covered the majority of the Central Valley (scenes p44r34, p44r33, p43r34, and p42r35). We downloaded images at EarthExplorer (http://earthexplorer.usgs.gov/) from three sources: Landsat 5 Thematic Mapper for 2006-2012, Landsat 7 Enhanced Thematic Mapper for 2012-2013, and Landsat 8 Operational Land Imager for 2013-2015. For Landsat 5 and Landsat 8, we used an approach developed by Reiter et al. (2015) to delineate the distribution of water and non-water cells for each image; this approach utilized scenes that were normalized to control for variation in reflectance measures between scenes, and then the presence of water for each cell was predicted using Bernoulli boosted regression models that were validated with groundtruth data. We used Landsat 7 images for 2012 and 2013 because neither Landsat 5 nor 8 images were available for those years. To process Landsat 7 images, we used the model developed by Schaffer-Smith et al. (2017) that resulted in high measures of accuracy and correspondence (both $>98 \%$ ) when applied to a Landsat 8 image. Processing was completed using Program R v3.1 (www.r-project.org) and ArcMap 9.3.1 (CESRI, Inc. 2009).

We calculated a monthly water availability index for each cell as the average probability of occurrence of surface water within the cell over a 10 -year period (2006-2015). We used average values to represent habitat because cloud cover limited mapping of water in some months and years of our study. Water availability indices were calculated by averaging all images from a single month, and then averaging across years using the 'raster' package (Hijmans and van Etten 2014). Depending on cloud cover and the position within a scene (scenes typically overlap along their border), the monthly average estimates for each cell comprised between 0 and 4 images and water availability indices were comprised of between 0 and 10 monthly average estimates.

\section{Habitat classification}

We used spatial datasets on land cover to identify a single, static habitat type for each cell. We focused on habitat types with potential for use by shorebirds when flooded. We defined suitable habitats as all managed wetlands and the following agricultural types: rice, grass/pasture, corn, field crops, row crops, and unknown agriculture types. We classified wetland and rice habitat types using a map of seasonal and semipermanent wetlands derived from a combination of satellite imagery, aerial photography, and other spatial data (Petrick et al. 2014). We then classified other habitat types using a map of land cover types averaged from satellite imagery over an eight year period (2007-2014; www.cropscape.gov; unpubl. data, The Nature Conservancy). Unsuitable land cover 
types, including developed, vineyard, and orchard, were masked from calculations of water variability indices.

\section{Shorebird location and movement data}

We used locations and movements of radio-tagged shorebirds along with water distribution maps to estimate residency rates in capture regions, functional connectivity between regions, and associations between movement distances and water distribution indices. We defined an individual movement as consisting of two consecutive locations for an individual shorebird; an initial point location $(a)$ followed by a subsequent point location $(b)$. We identified movements between regional habitat complexes and defined a movement between habitat patches as being longer than the regional mean patch size for location $a(100 \mathrm{~m}$ movement distance $=1$ ha mean patch size $)$ plus mean error distance (1007 $\mathrm{m})$.

\section{Seasonal residency and functional connectivity}

We quantified residency rates and functional connectivity by estimating an individual probability of occurrence within each region. We considered probability of occurrence estimates to be a reasonable proxy for seasonal residency rates within capture regions as well as functional connectivity to other regions. We used logistic regression to calculate each estimate as the probability that an individual bird would have $\geq 1$ detection within a region conditional on species, capture region, and season. Seasons were defined as winter ( $<4$ March) or spring ( $\geq 4$ March; Barbaree et al. 2015). We considered differences in probability of occurrence to be significant if their bootstrapped $95 \%$ confidence intervals (CIs) did not overlap.

\section{Movement analyses}

We used a set of linear mixed models to evaluate the influence of temporal and water distribution factors measured at multiple scales on movement distances (Zuur et al. 2009). We calculated movement distances as the Euclidean distance between locations $a$ and $b$ and $\log$ transformed distances to meet the assumptions of normality and homogeneity prior to modelling. We omitted movements from our analyses if both locations ( $a$ and $b$ ) occurred in April because calculation of water variability indices would require the use of water availability indices from May (for month-to-month changes) when occurrence in California is rare for dunlin (Warnock and Gill 1996) and dowitchers (Takekawa and Warnock 2000).

We evaluated 72 linear mixed models with movement distance data grouped by species and capture region prior to analysis. Each group included an intercept-only model as well as models with temporal or landscape factors as fixed effects, resulting in 18 models within each group (Table 1). We evaluated fixed factors separately because of high correlation between and within temporal and water distribution factors (Pearson's correlation coefficient $\geq 0.50$ ). For each individual movement, we attributed temporal factors associated with location $b$ (date, season) to represent the timing of a movement and water variability indices associated with location $a$ to evaluate the response of shorebirds to their surrounding landscape. Landscape covariates included three water variability indices that characterized month-to-month changes in the water availability index ( $\Delta$ water) and structural connectivity of reliable surface water ( $\Delta a g$ gregation, $\Delta$ patch). Calculating $\Delta$ patch and Aaggregation required binary cell values (water availability indices were continuous values); thus, we reclassified monthly water availability indices $(\geq 0.50$ water index $=1=$ water; $<0.50=0=$ no water) prior to analysis to represent a conservative estimate of cells with reliable surface water that were likely flooded during the drought-affected years of this study. We identified the clumpiness index (used to calculate Aaggregation) as the ideal proxy for structural wetland connectivity because it measured the fragmentation of surface water or the likelihood that cells adjacent to a water cell would also be classified as water cells. The clumpiness index was not confounded by the area of water within the measured landscape, which is an important caveat when calculating mean patch size (McGarigal et al. 2012). Landscape covariates were calculated at four separate scales around location $a$ using a regional boundary and 2, 5, and $10 \mathrm{~km}$ radius buffers (Elphick 2008; Reiter et al. 2015). All models included sampling interval as a fixed effect to control for variation in the number of days between locations $a$ and $b$ of a movement and the individual bird as a random effect to account for repeated observations of the same individual. 
Table 1 Summary of covariates used as fixed effects in linear mixed models with movement distance as the response variable

\begin{tabular}{|c|c|c|c|}
\hline Fixed effect & Data type & $\begin{array}{l}\text { Factor } \\
\text { type }\end{array}$ & Definition \\
\hline $\begin{array}{r}\text { Sampling } \\
\text { interval }\end{array}$ & $\begin{array}{l}\text { Continuous } \\
(1-107)\end{array}$ & Temporal & $\begin{array}{l}\text { Days between locations } a \text { and } b \text { (consecutive locations) for an individual } \\
\text { movement by a radio-tagged shorebird }\end{array}$ \\
\hline Date & $\begin{array}{l}\text { Continuous } \\
(1-168)\end{array}$ & Temporal & Day of location $b$; day 1 was 12 Nov each year \\
\hline Season & Binary & Temporal & Winter ( $<$ day 120 ) or spring ( $\geq$ Day 121$)$; season of location $b$ \\
\hline Year & 2 or 3 Level factor ${ }^{a}$ & Temporal & Nov-Apr 2012/2013, 2013/2014, and 2014/2015 \\
\hline$\Delta$ water & $\begin{array}{l}\text { Continuous }(-1.0 \\
\text { to } 1.0)\end{array}$ & Landscape & $\begin{array}{l}\Delta w a t e r=\text { average water index in region or buffer } \mathrm{x}_{\mathrm{x}+1}-\text { average water index in } \\
\text { region or buffer } \mathrm{x}\end{array}$ \\
\hline Daggregation & $\begin{array}{l}\text { Continuous }(-1.0 \\
\text { to } 1.0)^{\mathrm{b}}\end{array}$ & Landscape & $\begin{array}{l}\Delta \text { aggregation }=\text { clumpiness index in region or buffer } r_{x+1}-\text { clumpiness index in } \\
\text { region or buffer } r_{x}\end{array}$ \\
\hline$\Delta p a t c h$ & Continuous & Landscape & $\begin{array}{l}\Delta \text { patch }=\text { mean patch size }\left(\text { ha) in region or } \text { buffer }_{\mathrm{x}+1}-\text { mean patch size in }\right. \\
\text { region or buffer }\end{array}$ \\
\hline
\end{tabular}

${ }^{a}$ Shorebirds radio tagged over 3 years in Sacramento Valley and two years in San Joaquin Basin

b -1.0 represents maximum disaggregation, zero a random distribution, and 1.0 maximum aggregation

$\cdots \mathrm{x}$ Month of location $a$

We calculated Akaike's Information Criterion corrected for small sample sizes (AICc; Burnham and Anderson 2002) for each model and then compared models within each group and three subgroups by calculating the difference in AICc $(\triangle \mathrm{AICc})$ between all models and the top model. Subgroups included models with temporal factors, linear and polynomial terms for date, and landscape factors categorized by scale of measurement. Top models for each group had the lowest AICc values (Gelman and Hill 2006) and we considered models within $\leq 2 \Delta$ AICc of the top model to be in the competing model set. We determined individual variables to be significant if the $95 \%$ CI of the estimated parameter value did not overlap zero. Lastly, we calculated a marginal $R^{2}\left(\mathrm{~m} R^{2}\right)$ and a conditional $R^{2}\left(\mathrm{c} R^{2}\right)$ for each model to estimate the total variance explained by fixed effects and both fixed and random effects, respectively (Nakagawa and Schielzeth 2013). All analyses were conducted using Program R v3.2.5 and package lme4 (Bates et al. 2014).

\section{Results}

Water and habitat distributions

Monthly habitat maps showed the highest average water availability indices occurred in January and the lowest in April (Fig. 2). The relative proportion of suitable wetland and agricultural habitats was similar between regions: 0.62 in Sacramento Valley, 0.60 in Yolo-Delta, and 0.52 in San Joaquin Basin. However, the relative proportion of suitable habitats with flooding (water availability index $>0$ ) decreased from north to south: 0.74 in Sacramento Valley, 0.56 in Yolo-Delta, and 0.37 in San Joaquin Basin. Monthly average water availability indices varied considerably from January (0.31) to April (0.08) in Sacramento Valley, while variation in water index was relatively minimal from November to April in San Joaquin Basin (0.02-0.04). The range in monthly mean patch size for Sacramento Valley was 19.18 ha (9.47 ha in February to 28.65 ha in April), whereas the range for San Joaquin Basin was 6.45 ha (21.78 ha in January to 28.23 ha in April; Fig. 3). 

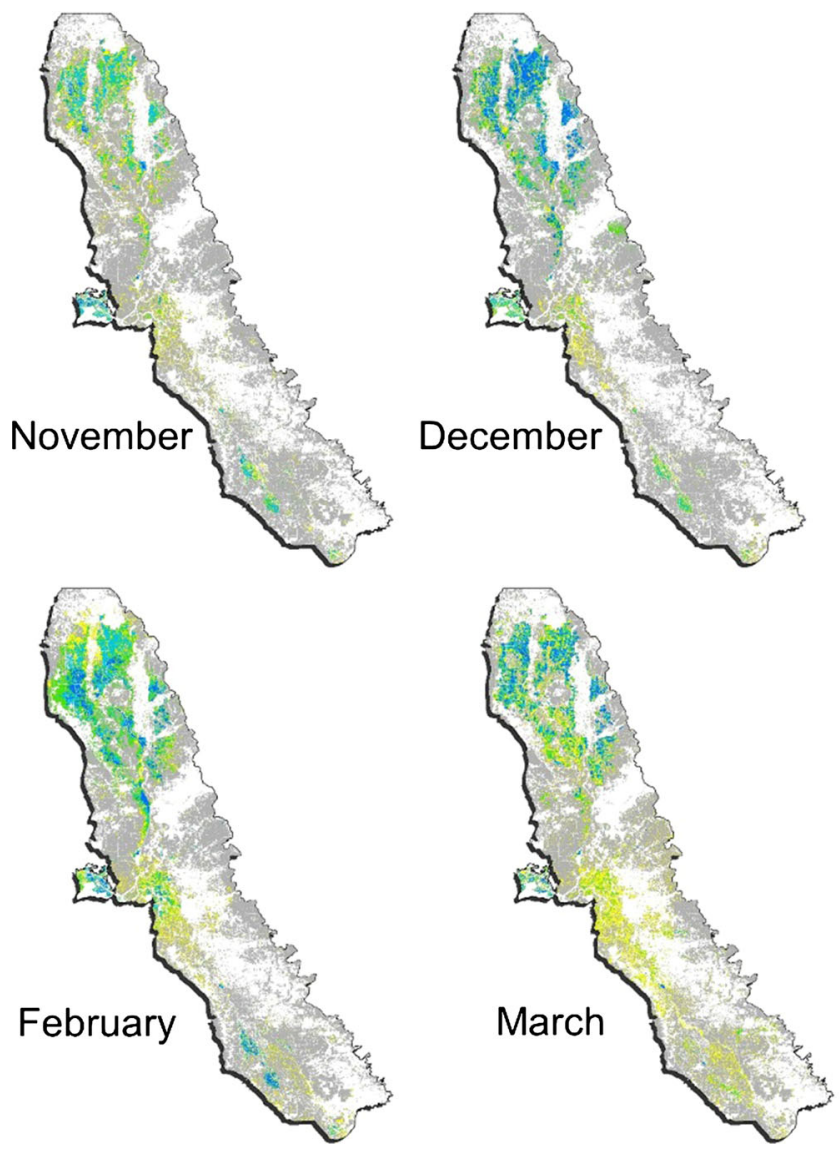

Fig. 2 Monthly average water availability index maps estimated using Landsat imagery from 2006 to 2015 of the Central Valley, California, USA. Water index values represented the

Regional connectivity and seasonal residency

We recorded 1554 locations for radio-tagged birds during aerial surveys from 24 November-29 April (mean $=5.85$ detections/bird, 95\% CI 5.52, $6.08 ; n=265)$. Eight radio-tagged birds were not detected after capture. We identified 1,539 movements after capture and the mean sampling interval between locations $a$ and $b$ of a movement was $17.08 \mathrm{~d}(95 \% \mathrm{CI}$ $12.39,21.76 \mathrm{~d})$. It was common for birds captured in Sacramento Valley to move to $\geq 1$ other region $(0.46$, $95 \%$ CI $0.36,0.51 ; n=163)$, but only a single bird from San Joaquin Basin was located within another region $(0.01,95 \%$ CI $0.00,0.30 ; n=102)$; a dowitcher radio-tagged at Merced NWR in the far eastern portion of GEA moved to Sacramento Valley shortly after capture in late November and remained there
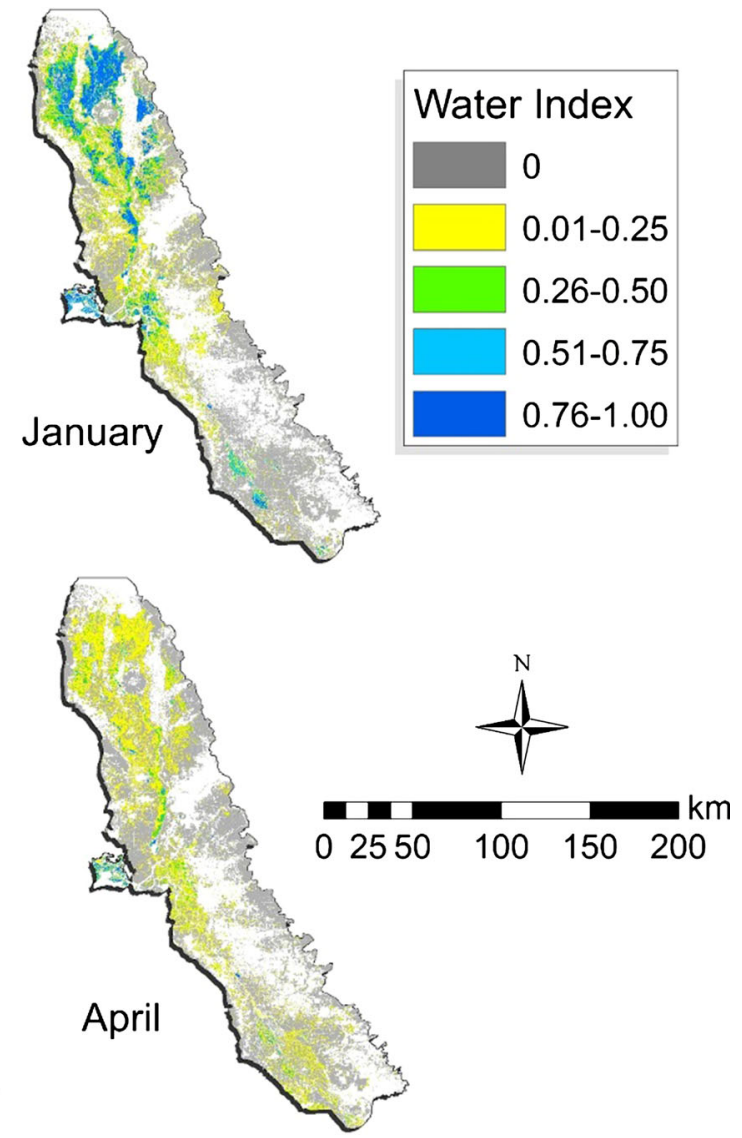

presence or absence of surface water averaged within months and then across years for each $30 \times 30 \mathrm{~m}$ cell. White areas represent habitat types considered unsuitable for shorebirds

until at least March. In addition, a dunlin radio-tagged in Sacramento Valley was detected in the upper Klamath Basin along the California-Oregon border during a U.S. Fish and Wildlife Service aerial waterbird survey of Tule Lake NWR on 28 March 2014.

Residency rates within capture regions declined for all groups except dunlin from San Joaquin Basin (Fig. 4). Dowitchers moved between regions more frequently than dunlin. Dunlin had a lower probability of moving between regions during winter than spring. The probability of a between-region movement was higher for dowitchers $(0.17,95 \%$ CI $0.13,0.21$; $n=391)$ than for dunlin $(0.07,95 \%$ CI $0.05,0.09$; $n=584$ ) from Sacramento Valley. Sixty-seven of 108 movements that crossed regional boundaries were from Sacramento Valley to Yolo-Delta and 26 

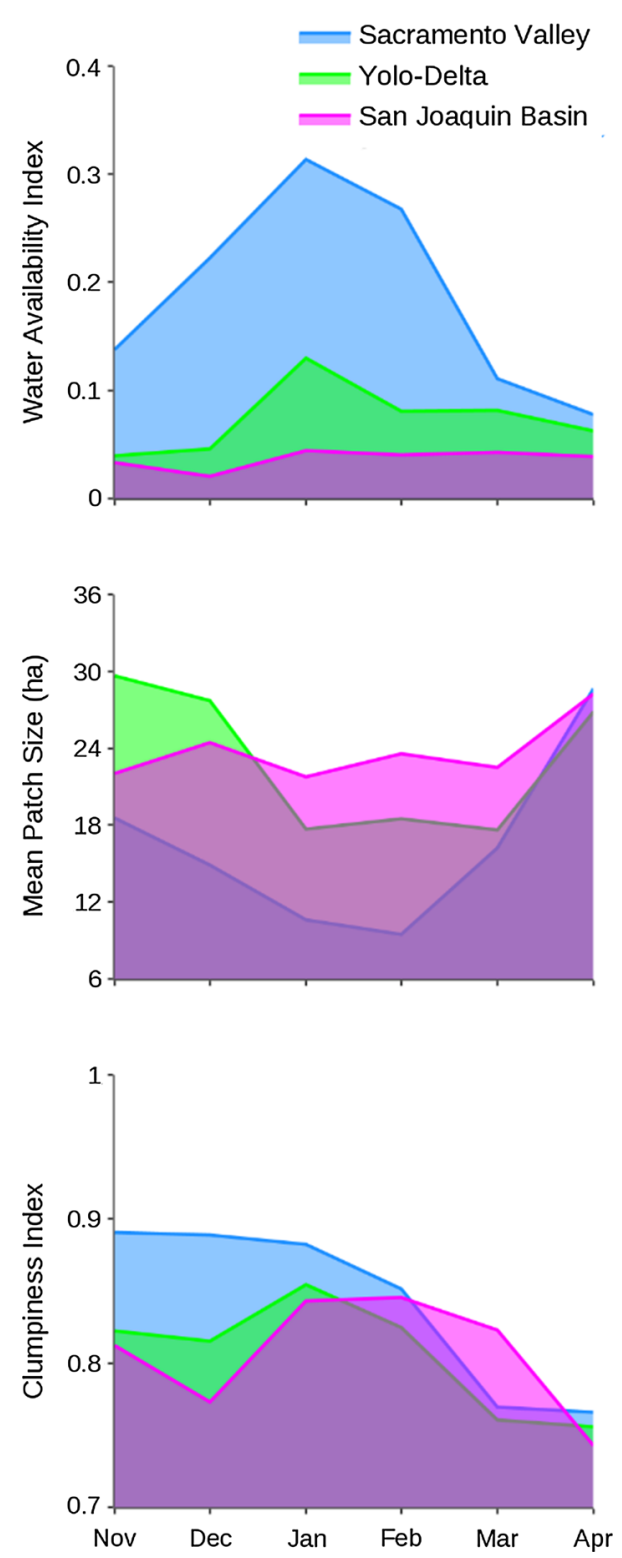

Fig. 3 Water distribution indices by month and region in the Central Valley, California, USA. Water availability indices calculated as the average presence of surface water within habitat types potentially suitable for shorebirds. Mean patch size and clumpiness index were calculated using binary values reclassified from water availability indices $(\geq 0.5=$ water and $<0.5=$ no water) to represent a conservative estimate of structural connectivity during drought

movements were from Sacramento Valley to San Joaquin Basin. Detections within the Sacramento Valley were widespread and similar to results in Barbaree et al. (2016). A single detection in San
Joaquin Basin $(n=598)$ occurred outside the GEA boundary when a dowitcher from Sacramento Valley was located using a managed wetland in San Joaquin River NWR on 18 March 2014; there were no detections in Mendota wetland complex. Of 130 detections in Yolo-Delta, 71 occurred within Yolo bypass and 39 in Suisun Marsh. Five dunlin from Sacramento Valley (two in 2013; three in 2014) were detected during spring surveys in San Pablo Bay (0.08, 95\% CI 0.01, 0.16; $n=59$ ).

\section{Movement distances and landscape associations}

Mean movement distances varied by month, species, and capture region (Fig. 5). Most movements were relatively short: $70 \%$ of 1539 movement distances were $<10 \mathrm{~km}$ (median $=4.3 \mathrm{~km} ; \min =0.002 \mathrm{~km}$, $\max =281 \mathrm{~km})$. Movement between habitat patches was likely for $75 \%$ of 974 movements by dunlin and dowitchers from Sacramento Valley and $41 \%$ of 565 movement by birds from San Joaquin Basin. Dowitchers and dunlin from Sacramento Valley moved farther on average than those from San Joaquin Basin. Mean movement distance increased from winter $(9.90 \mathrm{~km}, 95 \%$ CI $7.67,12.12 \mathrm{~km} ; n=429)$ to spring $(39.05 \mathrm{~km}, 95 \%$ CI $28.63,49.46 \mathrm{~km} ; n=154)$ for dunlin captured in Sacramento Valley, but there was no seasonal increase for other groups. The longest monthly mean movement distances coincided with an increasing mean patch size and decreasing clumpiness index from February to April in Sacramento Valley.

Model results varied by species, capture region, and scale of measurement (Appendix 1a-d). For dowitchers and dunlin from Sacramento Valley, movement distances increased with decreasing average surface water, decreasing mean patch size, and less aggregated surface water (Fig. 6). The top overall model sets were: Date $\times$ Season $\times$ Year and Date $^{3}$ for dunlin from Sacramento Valley, Aaggregation at the regional scale for dowitchers from Sacramento Valley and dunlin from San Joaquin Basin, and Apatch at the $5 \mathrm{~km}$ radius scale for dowitchers from San Joaquin Basin. Temporal models performed better than landscape models for dunlin but not dowitchers. The top temporal model set for all groups included a linear or polynomial term for Date. There was evidence of a nonlinear relationship between movement distance and date for dunlin from both regions, whereas a linear relationship was best supported for dowitchers. 


\section{Sacramento Valley}

Long-billed Dowitcher
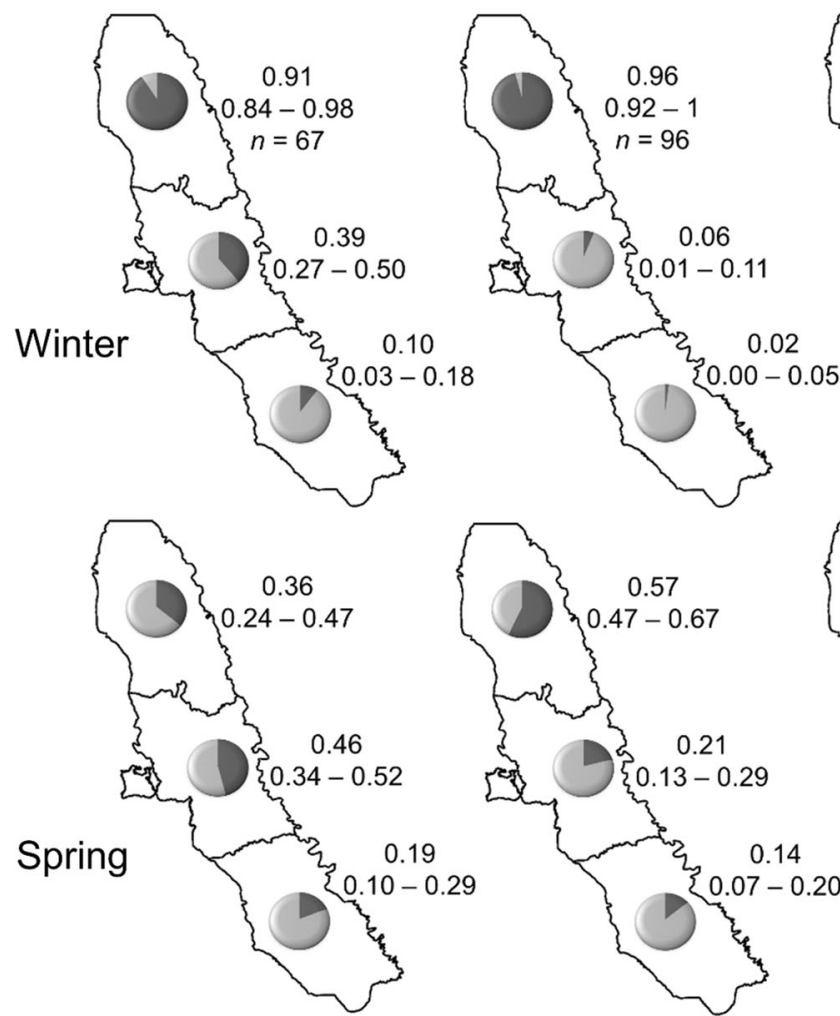

Fig. 4 Probability of occurrence for dunlin and long-billed dowitchers that were radio tagged within the Sacramento Valley (left columns) and San Joaquin Basin (right) in the Central Valley, California, USA. Estimates were calculated as the

There was a significant association between movement distance and $\Delta$ water for 13 of 16 models across groups. $\Delta$ water was a top model for 7 of 8 subgroups at the 2 and $5 \mathrm{~km}$ scales, whereas $\Delta$ patch or Aaggregation was a top model for 6 of 8 subgroups at the $10 \mathrm{~km}$ and regional scales; Aaggregation was only ranked as a top model when measured at the regional scale. Models had lower AICc values at larger scales of landscape measurement (10 km and regional) for dunlin and dowitchers from Sacramento Valley. Lower AICc values were mostly associated with smaller scales of measurement ( 2 and $5 \mathrm{~km}$ ) for dunlin and dowitchers from San Joaquin Basin, although the regional scale performed best for dunlin.

\section{San Joaquin Basin}

\section{Long-billed \\ Dowitcher}

Dunlin
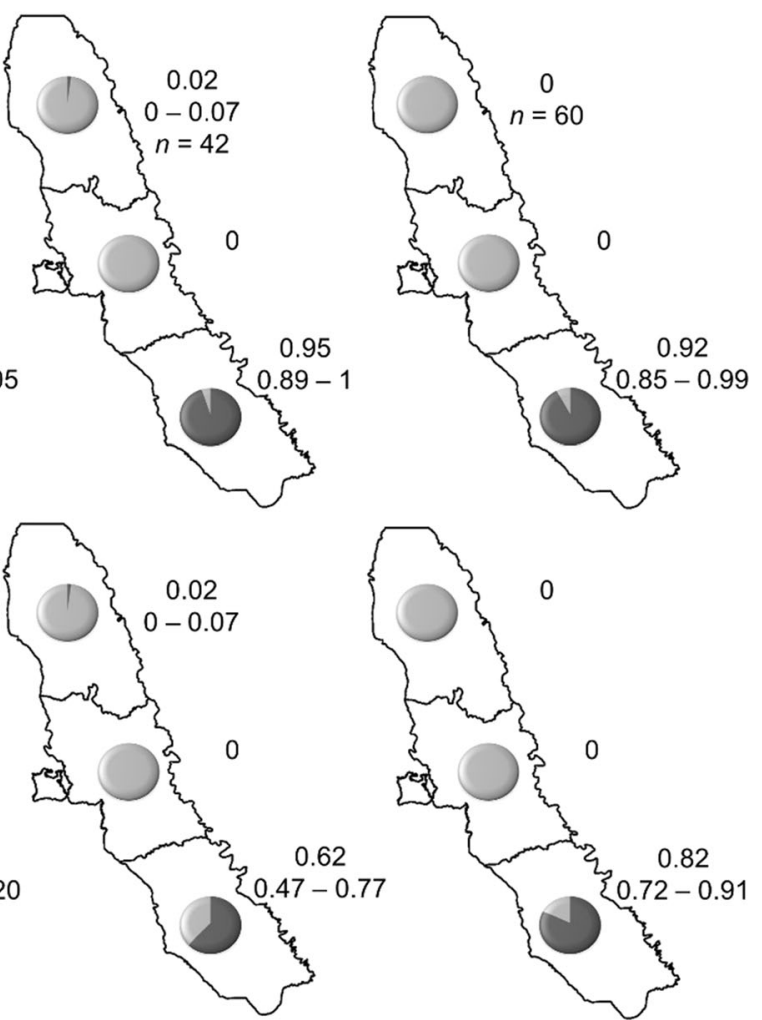

seasonal probability of an individual being located $\geq 1$ after capture in each region using logistic regression with $95 \%$ confidence intervals. Residency rates were estimates for an individual within its capture region

\section{Discussion}

Novel applications of remote sensing data can advance landscape ecology as well as understanding of ecological drivers that inform conservation decisions. By combining radio telemetry data from two species and satellite imagery from regions with distinct spatiotemporal habitat distributions, we were able to better understand relationships among movement decisions and variability in landscape structure. Specifically, we documented movement behaviors suggesting that landscapes with limited spatiotemporal variation in water distributions (structural connectivity) are beneficial for wintering migratory shorebirds. In this study, a stable and clumped regional water distribution was associated with higher 


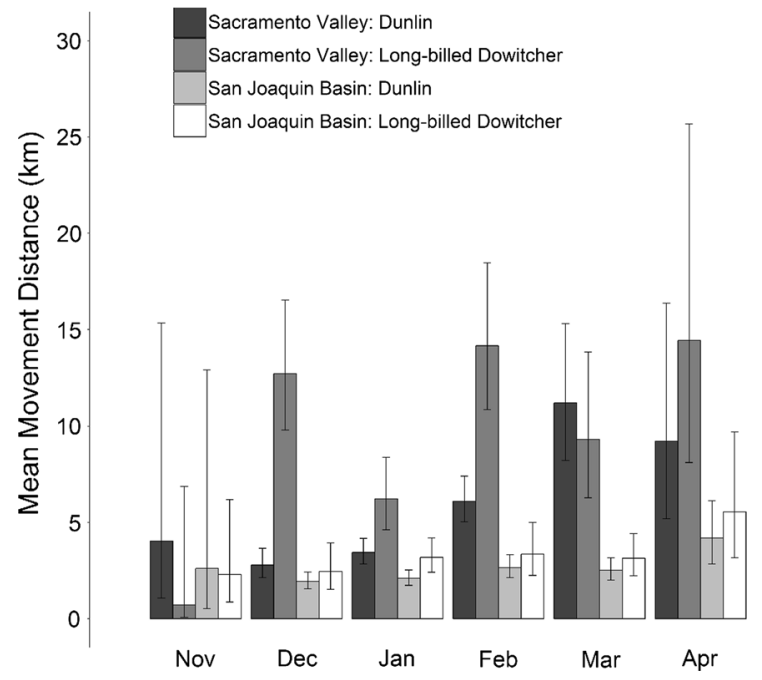

Fig. 5 Mean Euclidean movement distance between consecutive locations for shorebirds radio tagged in the Central Valley, California, USA. Error bars represent $95 \%$ confidence intervals of means

overwinter residency rates, lower functional connectivity to neighboring regions, and less frequent movement between habitat patches when compared to a region with a spatiotemporally variable and widespread water distribution. Whenever habitat availability decreased within a patch of flooded habitat during our study, departing that patch may have been the optimal response for an individual shorebird, in accordance with density dependent habitat selection theories (Jonzén et al. 2004). However, there was likely a suboptimal change in the surrounding resource distribution if that same individual would have continued to use the habitat patch otherwise (Hancock and Milner-Gulland 2006).

Movement data in our study were representative of movements by wintering shorebirds during an ongoing drought in the Central Valley that resulted in reduced freshwater available for flooding wetlands and agricultural lands during years two and three of the study (2013-2015; Reiter et al. 2018). Yet movements were highly correlated to changes in the 10-year average water distribution ( $\triangle$ water) and structural connectivity of reliable water (Apatch and Aaggregation). These correlations highlighted the importance of using remote sensing to monitor freshwater distributions and the utility of those data to predict movement behaviors of wetland-dependent wildlife, habitat quality, and regional population distributions (e.g.,
Shuford et al. 1998). Additionally, because the longterm average was a good predictor during drought years, among year variation in movement patterns for wintering shorebirds in the Central Valley may be minimal when compared to the high variability of within year water distributions from November to April. Ultimately, our results suggested that fundamental aspects of habitat quality for wintering shorebirds include the average presence and reliability of surface water as well as variation in structural connectivity of habitat patches.

Shorebird movements and landscape structure

Our study highlighted the fundamental relationship between shorebird movements and the presence of a reliable water landscape. We found that increasing movement distances were associated with decreasing water availability and structural connectivity of habitat patches. We also found that regions with different resource distributions resulted in distinctly different movement behaviors. In San Joaquin Basin where habitat was spatially clumped in GEA and landscape structure was temporally stable, longer movements between regions were essentially non-existent for wintering shorebirds. Residency rates within the GEA wetland complex were similar to those documented in other predictable landscapes such as San Francisco Bay where habitat availability is primarily governed by regular daily tidal cycles (Warnock and Takekawa 1996). Moreover, GEA served as refuge for wintering shorebirds emigrating from Sacramento Valley and potentially other nearby regions prone to periods of reduced habitat availability and structural wetland connectivity.

Conversely, a widespread but ephemeral water distribution in Sacramento Valley was associated with declining seasonal residency and frequent movement to other regions and habitat patches. The longest movement distances coincided with the lowest average amount and spatial aggregation of water on the landscape. Previous studies in patchily flooded agriculture-wetland mosaics of western North America also identified declining overwinter residency from January to March but were unable infer functional connectivity to nearby regions (Sanzenbacher and Haig 2002; Barbaree et al. 2015). Support for movement models with season and year interactions, as well as non-linear models, highlighted the substantial 


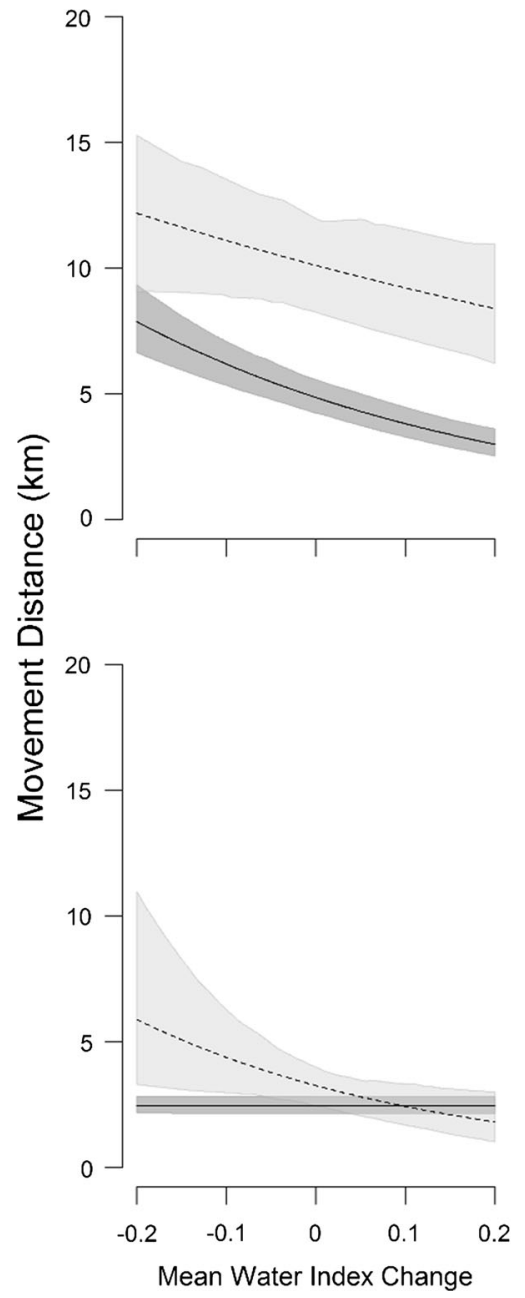

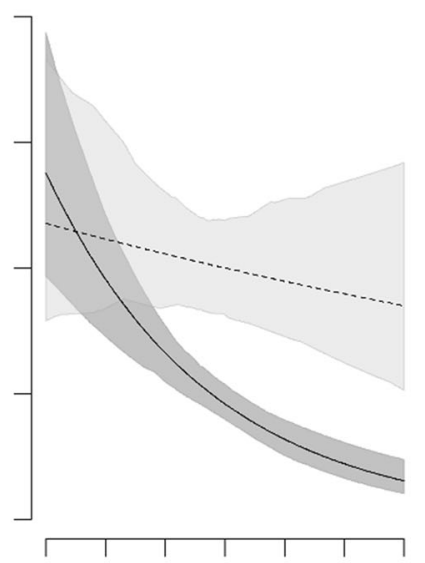
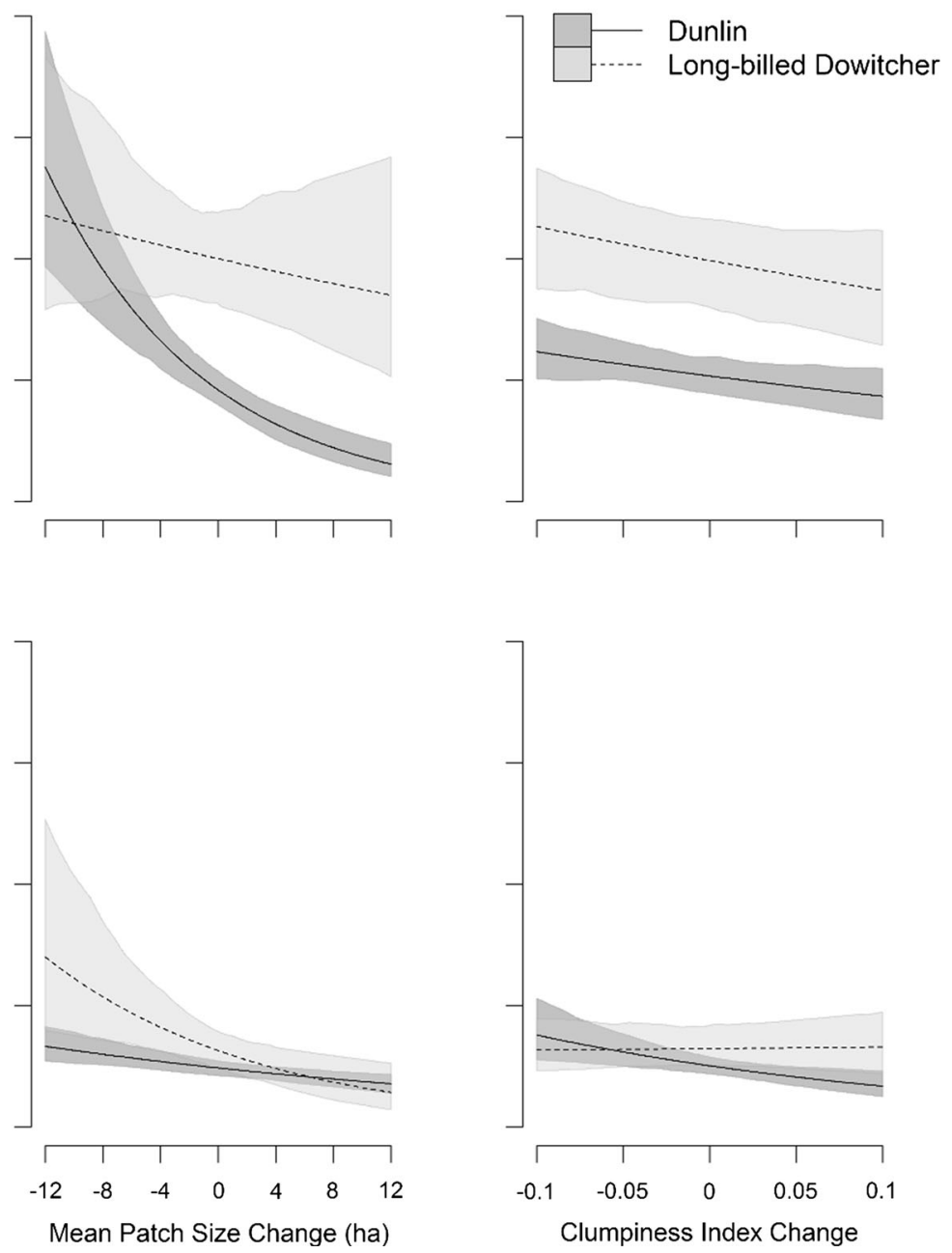

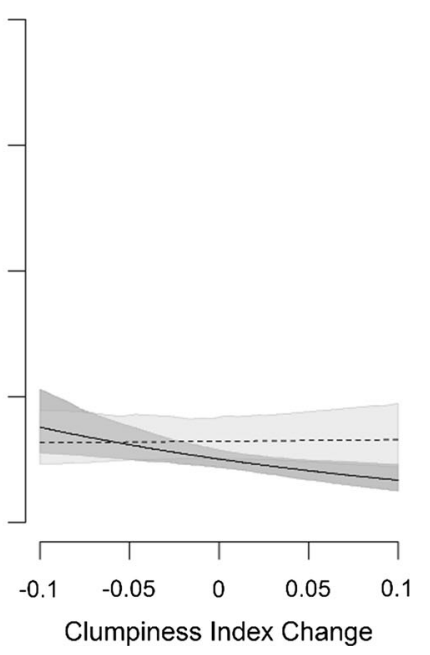

Fig. 6 Predicted movement distances for dunlin and longbilled dowitchers in Sacramento Valley (top row) and San Joaquin Basin (bottom) within the Central Valley, California, USA, as a function of water availability and aggregation metrics. Movement distances were predicted using

variability of freshwater distributions in Sacramento Valley. The predictable removal of water from rice fields was likely the primary cause of seasonal variation of movement behaviors, while variation among years may have been related to increasing effects of drought. The nonlinear trends in movement distance over time for dunlin suggested their movements were more closely related to fluctuations in habitat availability when compared to movements by dowitchers.

Most movement distances were short $(<10 \mathrm{~km})$ and those movements were primarily associated with parameter estimates from linear mixed models. Water variability indices on $\mathrm{x}$ axes were measured using a $10 \mathrm{~km}$ radius buffer around the location where each movement by a radio-tagged shorebird originated

changes in habitat availability at small scales $(<10 \mathrm{~km})$. These findings suggest wintering shorebirds were primarily utilizing habitat patches within close proximity when possible. Longer movement distances were more closely associated with spatial configuration of habitats at broad scales $(\geq 10 \mathrm{~km})$, which suggests that birds were interpreting the structural connectivity of habitat when selecting new complexes of flooded habitat patches. In Sacramento Valley, we found larger landscape measurements (regional and $10 \mathrm{~km}$ ) had higher correlation to movement distances, which was similar to previous studies 
in the region on landscape effects and shorebird abundance (Elphick 2008; Reiter et al. 2015). In contrast, smaller landscape measurements were the top predictors of movement distances in San Joaquin Basin, likely because a smaller extent of flooded habitats created a more homogeneous landscape when measured at larger scales. An important exception was for dunlin wintering in GEA, whose top predictor was aggregation of water measured at the regional scale. This result was unexpected because no dunlin radio tagged in San Joaquin Basin were located outside of the GEA wetland complex. Other important factors that may have influenced movement distances included predator abundance and average water depth of flooded habitats which relates inter-specific differences in habitat availability within the Central Valley (Isola et al. 2000).

Given the relationship between movement distances and structural connectivity at broad landscape scales, spatially aggregated and reliably flooded habitats that are located between larger wetland complexes may mediate the costs of longer movements between habitat patches. The Yolo-Delta region and San Joaquin River corridor play critical roles for functional wetland connectivity in California because they are located between three important wetland complexes recognized within the Western Hemisphere Shorebird Reserve Network (Sacramento Valley, GEA, San Francisco Bay; www.whsrn.org). Movements between Sacramento Valley and Yolo-Delta accounted for more than two-thirds of all movements between regions in our study. Emigration from Sacramento Valley via Yolo-Delta likely contributes to increased dunlin abundance in San Francisco Bay during April (Stenzel et al. 2002). Functional connectivity between the Central Valley and San Francisco Bay has also been documented for dunlin during February (Warnock et al. 1995) as well as dowitchers during December (Takekawa et al. 2002). Additionally, our evidence that a radio-tagged dunlin moved from Sacramento Valley to Klamath Basin during late March complemented evidence of functional connectivity between these regions documented for dowitchers during southward migration (Barbaree et al. 2016). This northward movement suggested that some early migrant dunlin likely overwinter in regions with declining habitat availability from February to April.
We found trends in mean patch size that signify the importance of considering the number and combined area of patches as well as spatial scale when interpreting mean patch size (Bender et al. 2003). The negative association between regional average water availability and mean patch size was somewhat counterintuitive. However, this association was most likely explained by the appearance of numerous isolated and individually flooded agricultural fields during peak flooding from December to February. Notably, the correlation between movement distance and mean patch size reversed from negative when measured using regional boundaries to positive when the landscape was measured using local scale buffers. The change in this relationship was likely related to the inclusion of more large patches of flooded wetlands when the landscape was measured using regional boundaries and only smaller or partial habitat patches being included in local landscape measurements.

Implications for wetland landscape planning

Our results support habitat configuration strategies to maximize the benefit of flooded wetlands and agricultural lands for wintering shorebirds in the Central Valley. We found that beneficial landscape structure for wintering was characterized by relatively large, contiguous habitat patches and limited spatiotemporal variability of surface water distributions. Shorebirds in our study depended on areas where the long-term average probability of surface water was highest, which highlighted the fundamental need for conservation strategies to ensure that freshwater is available to reliably flood wetlands and agricultural lands, especially those with a history of flooding.

Implementing a combination of landscape configuration concepts will be required for creating, restoring, and modifying wetland landscapes to benefit multiple species of wetland-dependent wildlife. Generally management plans should maximize structural wetland connectivity in order to minimize functional connectivity between regional complexes of flooded habitats and local habitat patches. First, flooded habitats should be spatially aggregated when possible to reduce the likelihood that a wintering shorebird departs a patch of flooded habitat. This requires prioritizing locations adjacent to reliably flooded wetlands or agricultural lands. Second, smaller 
patches of flooded habitat should be created or restored between larger patches to reduce the minimum distance between patches. We found dunlin were prone to overwinter residency within a single wetland complex, while dowitchers were more transient. This inter-specific difference in movement ecology suggests that larger habitat patches with highly aggregated water will disproportionally benefit dunlin, whereas shorter distances between habitat patches will benefit dowitchers. Lastly, landscape planning efforts should consider that month-to-month changes in mean patch size of $>6$ hectares from February to April were associated with substantial changes in movement behaviors by dowitchers and dunlin wintering in the Sacramento Valley.

The timing of flooding is another important consideration that can be controlled by humans within highly modified landscapes. Conservation efforts in the Central Valley should prioritize maintaining reliably flooded habitats through March and April. Increasing the number of patches of flooded habitat in Sacramento Valley and along likely flight corridors to nearby wetland complexes, such as Yolo-Delta and the San Joaquin River corridor, should help alleviate potential energy shortfalls during March and April prior to northward migration (Dybala et al. 2017). During this time period, shorebirds are especially vulnerable to the onset of reversible state effects because of elevated energy intake requirements to build fat reserves for migratory flights and subsequent breeding efforts (Marra et al. 1998; Lindström 2003; Senner et al. 2015). Effective conservation of migratory shorebirds in the Central Valley cannot be accomplished without dynamic strategies to flood potential habitats when and where shorebirds need it most.

Acknowledgements Support was provided by the S. D. Bechtel, Jr. Foundation in cooperation with the Migratory Bird Conservation Partnership, consisting of Point Blue Conservation Science, The Nature Conservancy, and Audubon California. Aerial surveys were provided by R. F. Van Wagonen in the Central Valley and P. Niewieroski in the San Pablo Bay area. We thank the U.S. Geological Survey Bird Banding Laboratory for their support; capture, banding, and radiotagging were covered under U.S. Fish and Wildlife Service permit \#09316. We thank the U.S. Fish and Wildlife Service for providing low-cost housing each year during capture efforts. For guidance and facilitating access to refuge wetlands, we thank M. Carpenter, J. Isola, K. Guerena, M. Peters, D. Wellington, and M. Wolder of the U.S. Fish and Wildlife Service and W. Cook, S. Miyamoto, and L. Sparks of California Department of Fish and Wildlife. We are grateful to landowners D. Bransford, J. Brennan, W. Carriere, M. Gallentine, W. Grissom, B. Montgomery, and J. Munger amongst others for providing access to their lands for capture efforts as well as R. Barbaree, J. Bosler, B. Campos, E. Condon, R. Cormier, C. Eyster, M. Gilbert, C. Gregory, D. Humple, M. Iglecia, S. Roberts, N. Seavy, K. Sesser, K. Velas, and S. Winquist for assisting with capture efforts. Constructive manuscript reviews were provided by N. Senner, C. Wisely, and one anonymous reviewer. This is Point Blue Conservation Science contribution number 2173.

Open Access This article is distributed under the terms of the Creative Commons Attribution 4.0 International License (http:// creativecommons.org/licenses/by/4.0/), which permits unrestricted use, distribution, and reproduction in any medium, provided you give appropriate credit to the original author(s) and the source, provide a link to the Creative Commons license, and indicate if changes were made.

\section{References}

Albanese G, Davis CA, Compton BW (2012) Spatiotemporal scaling of North American continental interior wetlands: implications for shorebird conservation. Landscape Ecol 27(10):1465-1479

Alves JA, Gunnarsson TG, Hayhow DB, Appleton GF, Potts PM, Sutherland WJ, Gill JA (2013) Costs, benefits, and fitness consequences of different migratory strategies. Ecology 94(1):11-17

Barbaree BA, Reiter ME, Hickey CM, Page GW (2015) Day and night habitat associations of wintering Dunlin (Calidris alpina) within an agriculture-wetland Mosaic. Waterbirds 38(1):40-46

Barbaree BA, Reiter ME, Hickey CM, Page GW (2016) Molt migration and migratory connectivity of the long-billed dowitcher. J Wildl Manag 80(2):256-265

Bates D, Maechler M, Bolker B, Walker S (2014) lme4: Linear mixed-effects models using Eigen and S4. $R$ package version 1 , no. 7

Bélise M (2005) Measuring landscape connectivity: the challenge of behavioral landscape ecology. Ecology 86:1988-1995

Bender DJ, Tischendorf L, Fahrig L (2003) Using patch isolation metrics to predict animal movement in binary landscapes. Landscape Ecol 18:17-39

Burnham KP, Anderson DR (2004) Multimodel inference: understanding AIC and BIC in model selection. Sociol Methods Res 33(2):261-304

Central Valley Joint Venture (2006) Central Valley Joint Venture implementation plan: conserving bird habitat. U.S. Department of the Interior, Fish and Wildlife Service, Sacramento, CA

Dettinger MD, Ralph FM, Das T, Neiman PJ, Cayan DR (2011) Atmospheric rivers, floods and the water resources of California. Water 3(2):445-478

Drake KR, Thompson JE, Drake KL, Zonick C (2001) Movements, habitat use, and survival of nonbreeding Piping Plovers. Condor 103(2):259-267 
Dybala KE, Reiter ME, Hickey CM, Shuford WD, Strum KM, Yarris GS (2017) A bioenergetics approach to setting conservation objectives for non-breeding shorebirds in California's Central Valley. San Franc Estuary Watershed Sci. https://doi.org/10.15447/sfews.2017v15iss1art2

Elphick CS (2008) Landscape effects on waterbird densities in California rice fields: taxonomic differences, scale-dependence, and conservation implications. Waterbirds 31(1):62-69

Elphick CS, Oring LW (1998) Winter management of Californian rice fields for waterbirds. J Appl Ecol 35(1):95-108

Elphick CS, Oring LW (2003) Conservation implications of flooding rice fields on winter waterbird communities. Agr Ecosyst Environ 94(1):17-29

Evans PR (1976) Energy balance and optimal foraging strategies in shorebirds: some implications for their distributions and movements in the non-breeding season. Ardea 64(1):117-139

Fahrig L (2007) Non-optimal animal movement in human-altered landscapes. Funct Ecol 21(6):1003-1015

Farmer AH, Parent AH (1997) Effects of the landscape on shorebird movements at spring migration stopovers. Condor 99:698-707

Fleskes JP (2012) Wetlands of the Central Valley of California and Klamath Basin. In: Batzer D, Baldwin A (eds) Wetland habitats of North America: ecology and conservation concerns. University of California Press, Berkeley, CA, pp 357-370

Frayer WE, Peters DD, Pywell HR (1989) Wetlands of the California Central Valley: status and trends. Report to US Fish and Wildlife Service, Portland, Oregon, USA

Gelman A, Hill J (2006) Data analysis using regression and multilevel/hierarchical models. Cambridge University Press, Cambridge

Goodwin BJ (2003) Is landscape connectivity a dependent or independent variable? Landscape Ecol 18(7):687-699

Griffin D, Anchukaitis KJ (2014) How unusual is the 2012-2014 California drought? Geophys Res Lett 41:9017-9023

Haig SM, Mehlman DW, Oring LW (1998) Avian movements and wetland connectivity in landscape conservation. Conserv Biol 12(4):749-758

Hancock PA, Milner-Gulland EJ (2006) Optimal movement strategies for social foragers in unpredictable environments. Ecology 87(8):2094-2102

Hijmans RJ, van Etten J (2014) raster: geographic data analysis and modeling. R package version 2:15

Isola CR, Colwell MA, Taft OW, Safran RJ (2000) Interspecific differences in habitat use of shorebirds and waterfowl foraging in managed wetlands of California's San Joaquin Valley. Waterbirds 1:196-203

Jonzén N, Wilcox C, Possingham HP (2004) Habitat selection and population regulation in temporally fluctuating environments. Am Nat 164:E103-E114

Kersten M, Piersma T (1987) High levels of energy expenditure in shorebirds; metabolic adaptations to an energetically expensive way of life. Ardea 75:175-187

Knowlton JL, Graham CH (2010) Using behavioral landscape ecology to predict species' responses to land-use and climate change. Biol Cons 143(6):1342-1354

Lindström $\AA$ (2003) Fuel deposition rates in migrating birds: causes, constraints and consequences. In: Berthold P,
Gwinner E, Sonnenschein E (eds) Avian Migration. Springer, Berlin, pp 307-320

Marra PP, Hobson KA, Holmes RT (1998) Linking winter and summer events in a migratory bird by using stable-carbon isotopes. Science 282(5395):1884-1886

McGarigal K, Cushman SA, Ene E (2012) FRAGSTATS v4: spatial pattern analysis program for categorical and continuous maps. Computer software program produced by the authors at the University of Massachusetts, Amherst. http:// www.umass.edu/landeco/research/fragstats/fragstats.html

Nakagawa S, Schielzeth H (2013) A general and simple method for obtaining R2 from generalized linear mixed-effects models. Methods Ecol Evol 4(2):133-142

Neumann W, Martinuzzi S, Estes AB, Pidgeon AM, Dettki H, Ericsson G, Radeloff VC (2015) Opportunities for the application of advanced remotely-sensed data in ecological studies of terrestrial animal movement. Mov Ecol 3(1):8

Petrick K, Fehringer D, Weverko A (2014) Mapping Seasonal Managed and Semi-permanent Wetlands in the Central Valley of California. Report to Central Valley Joint Venture by Duck Unlimited, Inc

Reiter ME, Elliott N, Veloz S, Jongsomjit D, Hickey CM, Merrifield M, Reynolds MD (2015) Spatio-temporal patterns of open surface water in the Central Valley of California 2000-2011: drought, land cover, and waterbirds. J Am Water Resour Assoc 51(6):1722-1738

Reiter ME, Elliott N, Jongsomjit D, Golet GH, Reynolds MD (2018) Impact of extreme drought and incentive programs on flooded agriculture and wetlands in California's Central Valley. PeerJ Preprints 6:e26483v1

Reynolds MD, Sullivan BL, Hallstein E, Matsumoto S, Kelling S, Merrifield M, Fink D, Johnston A, Hochachka WM, Bruns NE, Reiter ME, Veloz S, Hickey C, Elliott N, Martin L, Fitzpatrick JW, Spraycar P, Golet GH, McColl C, Morrison SA (2017) Dynamic conservation for migratory species. Sci Adv 3(8):e1700707

Roshier DA, Robertson AI, Kingsford RT, Green DG (2001) Continental-scale interactions with temporary resources may explain the paradox of large populations of desert waterbirds in Australia. Landscape Ecol 6(6):547-556

Roshier DA, Doerr VA, Doerr ED (2008) Animal movement in dynamic landscapes: interaction between behavioural strategies and resource distributions. Oecologia 156(2):465-477

Sanzenbacher PM, Haig SM (2002) Residency and movement patterns of wintering Dunlin in the Willamette Valley of Oregon. Condor 104(2):271-280

Schaffer-Smith D, Swenson JJ, Barbaree BA, Reiter MA (2017) Three decades of Landsat-derived spring surface water dynamics in an agricultural-wetland mosaic; implications for migratory shorebirds. Remote Sens Environ 193:180-192

Senner NR, Conklin JR, Piersma T (2015) An ontogenetic perspective on individual differences. Proc R Soc B 282:20151050

Shuford WD, Page GW, Kjelmyr JE (1998) Patterns and dynamics of shorebird use of California's Central Valley. Condor 1:227-244

Stenzel LE, Hickey CM, Kjelmyr JE, Page GW (2002) Abundance and distribution of shorebirds in the San Francisco Bay area. Western Birds 33(2):69-98 
Taft OW, Haig SM (2006) Importance of wetland landscape structure to shorebirds wintering in an agricultural valley. Landscape Ecol 21(2):169-184

Taft OW, Sanzenbacher PM, Haig SM (2008) Movements of wintering Dunlin Calidris alpina and changing habitat availability in an agricultural wetland landscape. Ibis 150(3):541-549

Takekawa JY, Warnock N (2000) Long-billed Dowitcher (Limnodromus scolopaceus). In: Poole A, Stettenheim P, Gill F (eds) The Birds of North America, vol 493. The Birds of North America, Inc, Philadelphia, pp 1-19

Takekawa JY, Warnock N, Martinelli GM, Miles AK, Tsao DC (2002) Waterbird use of bayland wetlands in the San Francisco Bay estuary: movements of long-billed dowitchers during the winter. Waterbirds 1:93-105

Tischendorf L, Fahrig L (2000) On the usage and measurement of landscape connectivity. Oikos 90(1):7-19

Toral GM, Aragonés D, Bustamante J, Figuerola J (2011) Using Landsat images to map habitat availability for waterbirds in rice fields. Ibis 153(4):684-694
Warnock N, Gill RE (1996) Dunlin (Calidris alpina). In: Poole A, Gill E (eds), The Birds of North America, No. 203. The Academy of Natural Sciences, Philadelphia, PA, and the American Ornithologists' Union, Washington, DC, USA

Warnock SE, Takekawa JY (1996) Wintering site fidelity and movement patterns of Western Sandpipers Calidris mauri in the San Francisco Bay. Ibis 138:160-167

Warnock N, Page GW, Stenzel LE (1995) Non-migratory movements of Dunlins on their California wintering grounds. The Wilson Bulletin 1:131-139

Webb EB, Smith LM, Vrtiska MP, Lagrange TG (2010) Effects of local and landscape variables on wetland bird habitat use during migration through the Rainwater Basin. J Wildl Manag 74(1):109-119

Wiens JA (1989) Spatial scaling in ecology. Funct Ecol 3(4):385-397

Zuur AF, Ieno EN, Walker NJ, Saveliev AA, Smith GM (2009) Mixed effects models and extensions in ecology With R. Springer, New York, NY, USA 